\title{
Production and Application on English Micro Video Teaching Resources Xiuli Gou ${ }^{a}$, Peng Zhang ${ }^{b}$ \\ College of Foreign Languages, Bohai University, Jinzhou, 121013, China \\ a1029915835@qq.com, b'zhangpeng44444@126.com
}

Keywords: English teaching; micro video; teaching resources; production principle; production tools; production process; application strategy

\begin{abstract}
As a new teaching resource has the advantages of short teaching time, vivid image, and the complexity of the curriculum content, Micro video adapted to the actual needs of English teaching. This paper based on the theory of software development and multimedia learning cognitive theory. The research content includes the production principle, the production tools, the production process, the application strategy and so on in production and application on English micro video resources. We can develop a wide variety of English teaching resources by using the research results of this paper, which can help learners to understand and solve problems, and to improve the quality of English teaching.
\end{abstract}

\section{Introduction}

The teaching of College English course, which is issued by the Ministry of education, points out that all colleges and universities should make full use of modern information technology, based on computer and classroom teaching mode to improve the teaching of teachers in a single teaching mode. Micro video English teaching resource is applied to English teaching, which accords with the development direction of modern educational technology. The change of English teaching mode is not only the change of teaching method and teaching means, but also the change of teaching idea and practice. The teaching ideas and practices that are to be realized from the teachers as the center, the simple to teach the language knowledge and skills, to the students as the center. Both to teach language knowledge and skills, pay more attention to the cultivation of practical ability of language learning and autonomous learning ability of the teaching ideas and practice, but also to cultivate students' ability to lifelong learning for lifelong education [1,2].

The classroom teaching based on the micro video teaching resources can make the learning content of the subject become vivid, intuitive, and hence cause the learners to learn the content of attention and improve the learning enthusiasm of the learners [3]. The contents was presented in the traditional classroom such as books, materials or other paper materials. It is in a single form and the learners are prone to fatigue. English is a language. Learning English is applied in real life. Each link of listening, speaking, reading, writing and so on can not be ignored. Using micro video teaching resources, learners can carry out micro video viewing in the classroom. It is conducive to the improvement of the ability of learners. When learns encountered a key and difficult, learning after the lesson.

\section{Research Status}

The research on micro video is focused on the interaction, entertainment, education and fast, which is based on the perspective of communication science. A increasing attraction of Micro video with wonderful content, vivid picture, easy availability and strong interactivity, has a huge impact on the traditional media. YouTube is considered to be the starting point of the micro video, the use of Flash technology to provide micro video, including movie clips, video clips, video recordings, as well as daily video clips, etc.. Since it has the advantages of sharing resources, rich content and high transparency, it has been popular in the world. The United States MIT to the excellent classroom teaching resources in the form of open class, such as the spirit of the education information era, it is particularly important, especially in the field of micro video as the representative of the sharing of 
educational resources to take the lead as a very good start. With the continuous sharing of network resources, Micro video teaching resources are used by more and more people. People can learn the various grades of school shared curriculum, overcome the geographical and time constraints through the network [3-6].

The same of micro video is that they are both in the perspective of communication studies in China. Different from foreign scholars, domestic scholars study the value orientation of the micro video resources and focus on the practical significance. The research directions of micro video are as follows: first, the research on how to express personal opinion and viewpoint with the help of the theory of micro video, two is the future development of micro video site has become a social, and even the frontier of academic research. How to make use of micro video assisted teaching, some scholars have proposed the idea of building a stable micro video site. Traditional campus TV play has some limitations. The use of micro video site can not only provide interactive platform for teachers and students to facilitate communication between teachers and students, and can break through the geographical restrictions, so that communication between teachers and students become more smoothly. At present, all subjects are actively using micro video teaching resources for teaching services. The research on micro video in China is more and more on the theory of communication.

Through foreign and domestic research on micro video analysis, it can be seen that, to date, the research of micro video is mostly dependent on the interactive and entertaining, the current micro video more is used in the field of communication, in the teaching of research and should be relatively small. Although the use of micro video teaching resources in the classroom has become the focus of information education, but there are still a lot of problems in the application of classroom and the need to urgently solve the problem: micro video as an educational resource, should not only be a fashion, or a pastime, should pay more attention to the value of its own. Some scholars believe that the micro video teaching is informal learning, that micro video teaching should not appear in the classroom, especially in the basic education stage, which is obviously wrong. Because of the essence of micro video, a teaching resource application in classroom understanding is not enough. Therefore, we need to analyze and explain micro video and the meaning of micro video as a teaching resource. Only fully grasp the connotation of micro video, in order to let the first line of teachers to give full play to the role of micro video as a teaching resource, which can make the micro video for the majority of teachers and students.

\section{Production Principle}

Micro video production should be scientific and accurate, moderate capacity, clear thinking, organization and orderly, showing the way to use ARCS motivation model for design. The ARCS model is divided into four categories: attention, relevance, confidence, satisfaction, which is a kind of strategic design model with practical operability. The motivation model of ARCS is modified, which can be used to design the contents of teaching micro video [7].

(1) Attract the attention of learners. As far as possible the use of a variety of forms, such as games, inquiry, conflict, humor, example, and more can be recorded in a formal situation to make the learner excited.

(2) The learners find the correlation between the contents of the micro video and the existing knowledge and life experience. Content can be used to solve the practical problems in life, can apply what they have learned; With personal experience, self selection, the status quo, and matching the requirements, play a role model, content organization helps students to understand.

(3) To establish and maintain the confidence of learners. We should fully consider the learner's learning rhythm, time and ability, clearly mark the learning goals and order, set obligatory and optional, recommend content, for learners of different levels to provide easy access to the chance of success, establishing complete confidence in learning; One to one guide recording mode better than a pair of multiple teaching, so that the students feel the teacher pay attention to their own in the side, and maintain self-confidence. 
(4) Let the learners learn to have the satisfaction from the success. In each section of the video settings, When the learners immediately answer in the consolidation of the previous knowledge, they can meet the satisfaction from success; We should do more longitudinal progress of the study than horizontal comparison, to avoid frustration.

\section{Production Tools}

Captivate Adobe is a screen recording software. Using the method is very simple, anyone who does not have programming knowledge or multimedia skills are able to quickly create powerful software demonstrations and training content [8].Using Captivate Adobe software, anyone who does not have programming knowledge or multimedia skills can develop interactive content. Without learning Flash, you can create a software demo based on Flash, through the automatic recording of screen operation and development software simulation. Adding electronic interaction, feedback fields, and custom tests. Create a scene based soft skills training, including a real appeal to the learner's rich media, you can use a simple click interface to quickly change the project. For software simulation, an application is began by recording. Captivate Adobe automatically creates a simulation or demonstration based on Flash, which is completed through the use of text subtitles, edited by the mouse movement and highlighted indication. Without any programming or scripting, you can include text entry fields, check boxes, keyboard shortcuts, and buttons that have more than one correct answer option, or add a specific interactive after capture [9], and then record the audio solution to enhance the electronic experience during the period of capture or after.

For curriculum developers, the advantages of Captivate include: intuitive interface, powerful, detailed and meticulous, provide Storyboard view, easy to understand the course of the branch structure. Timeline function, arrange all the elements of the time for each page; supporting for recording screen and inserting PPT of function, which can be used alone, also can be combined with the course; adding mouse of action, and define the time and sliding track, therefore meet different needs of the course.

Main functional module [10]: content editing, creating blank pages, adding text, pictures, sound, video, FLASH, super link, multimedia interactive, add audio, video, FLASH, interactive components, with screen capture and recording capabilities, capture and record screen activities, synchronized audio and video, and enhance the production of courseware. And we can record the mouse movement track to meet the needs of different courses; skills simulation, development and deployment of computer simulation and skills assessment; training based on the scene, the development of complex branches of the skills training courses; testing and evaluation to create, create and deploy interactive tutorial, create a question bank, random pumping test; Course publishing, the course can be published for a variety of formats on the local machine to browse the operation, such as web form, CD-ROM, or import LMS (learning management system) of the curriculum package file; track record, preset access to the course of the authority and student information, which do not need to support of external database. Record learning information by link with AICC or SCORM standard LMS platform convergence.

\section{Production Process}

The micro video development process is divided into five steps, as shown in Table 1.

Due to the characteristics of English subject, video teaching resources based on the content not only attaches importance to theory but also to the students to pay attention to how to apply the learning content, thus produced on the basis of micro video teaching resources need to combination of theory and practice, the micro development of video of the first stage is production of material and presentation, so in the development of video resources not only specific application process and the corresponding theory to explain. In the development of micro video, it will focus on the image of the abstract theoretical knowledge, so as to improve the interest of learners and improve their learning enthusiasm. 
Table. 1 Production process of micro video teaching resources

\begin{tabular}{|l|l|l|}
\hline Steps & Operation & Brief description \\
\hline Step 1 & $\begin{array}{l}\text { Material } \\
\text { preparation }\end{array}$ & $\begin{array}{l}\text { Prepare the teaching content ,words explain, syntax analysis } \\
\text { related to curriculum and a presentation made of these. }\end{array}$ \\
\hline Step 2 & Case selection & $\begin{array}{l}\text { A typical example of what is relevant to the content of the } \\
\text { study. }\end{array}$ \\
\hline Step 3 & $\begin{array}{l}\text { Micro video } \\
\text { recording }\end{array}$ & $\begin{array}{l}\text { Implementation of micro video recording based on the first two } \\
\text { steps. }\end{array}$ \\
\hline Step 4 & Add comments & Notes on the difficulty and important. \\
\hline Step 5 & $\begin{array}{l}\text { Modification } \\
\text { and }\end{array}$ & $\begin{array}{l}\text { To observe the effect of the teaching effect, the change of the } \\
\text { emotion, therefore according to the changes and the feedback } \\
\text { of the students to carry on the modification of micro video }\end{array}$ \\
\hline
\end{tabular}

\section{Application Strategy}

From the perspective of English teachers, students and software developers, the application strategy of micro video English teaching resources is as follows:

(1) Pay attention to the technical training of distance learning, improve the effect of students and the media interface of the operation interaction. The network teaching platform is relatively unfamiliar for most students, and teachers don't training students on systematic and strict technical in network school, which led to technical operation problems of the majority students, sometimes affect the learning results.

(2) The use of micro video should be less and refined, improve the interaction between students and learning resources. Micro video has a great role in improving learning interest. Because of the differences of students, a large number of micro video will increase the burden on students. So micro video more applications in the non book content, the time can be relatively long micro video. With a vivid, interactive features, can help students understand the textbook content of micro video. In addition, homemade micro video is certainly able to improve students' learning interest and efficiency, but, students want to have other forms of micro video for selection in the developed information today.

(3) Pay attention to the use of a variety of interactive tools and other resources to improve the students' and students' interaction with the teachers. The discussion area gives students a better exchange platform to express personal views, and to exercise the ability of students to raise questions, to think and to choose the answers. Other types of resources in the form of a teacher's processing of text information, in the process of promoting the students to have a very big role in the concept of interaction. In the interaction between the teachers and the students, the use of the platform can be used to improve the efficiency of solving the students' problems.

(4) Pay attention to the teaching interaction design, which ensure the students and the new concepts of the new concept of interaction. Through the experiment of this paper, it is found that the level of teaching interaction plays a key role in guiding the teaching design of the chapter [11]. Therefore, in practice, we should pay attention to the diversity of interactive mode, deepen the deep application of the interaction.

\section{Conclusion}

The development and application of micro video teaching resources has been a hot issue in the field of educational technology. After a few years of rapid development nearly, the promotion of teaching plays a positive role in promoting. The integration of micro video teaching resources in the traditional classroom teaching, is not abandoned or abandon the traditional teaching, but on the basis of traditional teaching, it makes full use of the advantages of micro video, making the two organic fusion. So it not only has the advantages of multimedia technology, but also improves the quality of teachers' classroom teaching [12]. From a theoretical point of view, through the 
combination of teaching theory and micro video technology, the experimental study on English teaching, the depth of research, enrich the existing knowledge about the generation of classroom teaching resources. From a practical point of view, in order to achieve the goal of optimizing the teaching of English and in depth study of the English classroom teaching mode, the results show that the effect of English teaching based on micro video teaching is more significant than that of the traditional English teaching.

\section{Acknowledgement}

This work is supported by social science fund project of Liaoning province: Construction and application on micro video English teaching resources platform (L14DYY029).

\section{References}

[1] Zhang Li, "Research on the application of micro video teaching resources in College English Teaching," Electronic Test, vol. 21, no. 14, pp. 149-150, 2014.

[2] WANG Bing-jie CHEN Ling WANG Xiao-feng, "Research on JiTT teaching practice based on micro video: Take the learning platform as an example," Modern Educational Technology, vol. 23, no. 4, pp. 24-29, 2013.

[3] Md. Mahedi Hassan, Poo Kuan Hoong, " Seamless handover integrated solution for video transmission over proxy mobile IPv6 in a micro mobility domain," Journal of Network and Computer Applications, vol. 36, no. 1, pp. 66-76, 2013. http://baike.baidu.com/link?url=F3DsPsorseZQQTbdeOC4xhna-XFwSjJ6QSho24RX2BvNNR LV7N7HwsVHmrqWotJeTraLl1pYrxXb8y1DMBFBO_, 2015-8-22.

[5] Neeraj Kanwar, Nikhil Gupta, K.R. Niazi, Anil Swarnkar, "Simultaneous allocation of distributed resources using improved teaching learning based optimization," Energy Conversion and Management, vol. 103, no. 10, pp. 387-400, 2015.

[6] Violeta Holmes, Ibad Kureshi, "Developing High Performance Computing Resources for Teaching Cluster and Grid Computing Courses," Procedia Computer Science, vol. 51, no. 1, pp. 1714-1723, 2015.

[7] J. Xiong, "Flipped classroom model for the design and production of Micro-video-based learning resources," Journal of Southwest University for Nationalities(Natural Science Edition), vol. 41, no. 3, pp. 350-355, 2015.

[8] E-Learning house, "Adobe Captivate," http://fuwu.aieln.com/tool/adobe_captivate/, 2015-8-3.

[9] Perihan Savas, " Micro-teaching Videos in EFL Teacher Education Methodology Courses: Tools to Enhance English Proficiency and Teaching Skills Among Trainees," Procedia - Social and Behavioral Sciences, vol. 55, no. 5, pp. 730-738, 2012.

[10] Baidu Encyclopedia, "Adobe Captivate," http://baike.baidu.com/link?url=VQrR_DrD5KtXGDf-4w61EXMnQCBXCjFysKcjen6ie_UvfJ CTReiZ9IEu6B-snxlJQWtBAdmQb5AxtKJuqTbEgq, 2015-8-22.

[11] Phoenix W.Y. Lam, Winnie Cheng, Kenneth C.C. Kong, " Learning English through workplace communication: An evaluation of existing resources in Hong Kong," English for Specific Purposes, vol. 34, no. 4, pp. 68-78, 2014.

[12] Y. Yan, "Micro blog and micro video: A new approach to college English learning," Journal of Taiyuan Urban Vocational College, vol. 15, no. 8, pp. 130-132, 2013. 